\title{
Association of Statewide Implementation of the Prehospital Traumatic Brain Injury Treatment Guidelines With Patient Survival Following Traumatic Brain Injury The Excellence in Prehospital Injury Care (EPIC) Study
}

Daniel W. Spaite, MD; Bentley J. Bobrow, MD; Samuel M. Keim, MD, MS; Bruce Barnhart, RN, CEP; Vatsal Chikani, MPH; Joshua B. Gaither, MD; Duane Sherrill, PhD; Kurt R. Denninghoff, MD; Terry Mullins, MPH, MBA; P. David Adelson, MD; Amber D. Rice, MD, MS; Chad Viscusi, MD; Chengcheng Hu, PhD

IMPORTANCE Traumatic brain injury (TBI) is a massive public health problem. While evidence-based guidelines directing the prehospital treatment of TBI have been promulgated, to our knowledge, no studies have assessed their association with survival.

OBJECTIVE To evaluate the association of implementing the nationally vetted, evidence-based, prehospital treatment guidelines with outcomes in moderate, severe, and critical TBI.

DESIGN, SETTING, AND PARTICIPANTS The Excellence in Prehospital Injury Care (EPIC) Study included more than 130 emergency medical services systems/agencies throughout Arizona. This was a statewide, multisystem, intention-to-treat study using a before/after controlled design with patients with moderate to critically severe TBI (US Centers for Disease Control and Prevention Barell Matrix-Type 1 and/or Abbreviated Injury Scale Head region severity $\geq 3$ ) transported to trauma centers between January 1, 2007, and June 30, 2015. Data were analyzed between October 25, 2017, and February 22, 2019.

INTERVENTIONS Implementation of the prehospital TBI guidelines emphasizing avoidance/treatment of hypoxia, prevention/correction of hyperventilation, and avoidance/treatment of hypotension.

MAIN OUTCOMES AND MEASURES Primary: survival to hospital discharge; secondary: survival to hospital admission.

RESULTS Of the included patients, the median age was 45 years, 14666 (67.1\%) were men, 7181 (32.9\%) were women; 16408 (75.1\% ) were white, 1400 (6.4\%) were Native American, 743 (3.4\% ) were Black, 237 (1.1\%) were Asian, and 2791 (12.8\%) were other race/ethnicity. Of the included patients, 21852 met inclusion criteria for analysis (preimplementation phase [P1]: 15 228; postimplementation [P3]: 6624). The primary analysis (P3 vs P1) revealed an adjusted odds ratio (aOR) of $1.06(95 \% \mathrm{Cl}, 0.93-1.21 ; P=.40)$ for survival to hospital discharge. The aOR was $1.70(95 \% \mathrm{Cl}, 1.38-2.09 ; P<.001)$ for survival to hospital admission. Among the severe injury cohorts (but not moderate or critical), guideline implementation was significantly associated with survival to discharge (Regional Severity Score-Head 3-4: aOR, 2.03; 95\% Cl, 1.52-2.72; $P<.001$; Injury Severity Score $16-24$ : aOR, $1.61 ; 95 \% \mathrm{Cl}, 1.07-2.48 ; P=.02)$. This was also true for survival to discharge among the severe, intubated subgroups (Regional Severity Score-Head 3-4: aOR, 3.14; $95 \% \mathrm{Cl}, 1.65-5.98 ; P<.001$; Injury Severity Score 16-24: aOR, 3.28; 95\% Cl, 1.19-11.34; $P=.02$ ).

CONCLUSIONS AND RELEVANCE Statewide implementation of the prehospital TBI guidelines was not associated with significant improvement in overall survival to hospital discharge (across the entire, combined moderate to critical injury spectrum). However, adjusted survival doubled among patients with severe TBI and tripled in the severe, intubated cohort. Furthermore, guideline implementation was significantly associated with survival to hospital admission. These findings support the widespread implementation of the prehospital TBI treatment guidelines.

TRIAL REGISTRATION ClinicalTrials.gov identifier: NCT01339702

JAMA Surg. 2019;154(7):e191152. doi:10.1001/jamasurg.2019.1152

Published online May 8, 2019.
Supplemental content

Author Affiliations: Author affiliations are listed at the end of this article.

Corresponding Author: Daniel W. Spaite, MD, Department of Emergency Medicine, The University of Arizona College of Medicine, 1501 N Campbell Ave, Tucson, AZ 85724 (dan@aemrc.arizona.edu). 
$\mathrm{T}$ he burden of traumatic brain injury (TBI) on US society is enormous: annually it leads to 2.2 million emergency department visits, 280000 hospitalizations, 52000 deaths, and more than $\$ 60$ billion in economic costs. ${ }^{1,2}$ While improving outcomes has been difficult, ${ }^{3-9}$ early treatment may help mitigate secondary brain injury, ${ }^{10-15}$ and this has led to promulgation of official evidence-based TBI treatment guidelines. ${ }^{10-12,15}$ There is limited in-hospital evidence supporting the effectiveness of guideline-based treatment. ${ }^{16-21}$ However, to our knowledge, association of implementation by prehospital emergency medical services systems (EMS) with overall survival has not been evaluated. ${ }^{11,12}$ The objective of this study was to implement the nationally vetted TBI guidelines ${ }^{11}$ among the EMS agencies of Arizona and to evaluate the association with outcomes in moderate, severe, and critical TBI.

\section{Methods}

Study Design, Setting, and Oversight

The Excellence in Prehospital Injury Care (EPIC) study was conducted throughout Arizona using a controlled, before-after, multisystem, intention-to-treat design. ${ }^{22-26}$ The methods have been reported in detail. ${ }^{27-30}$ The study phases were based on each EMS agency's training schedule: phase 1 (P1), preimplementation; phase 2, training (initiation to completion); and phase 3 (P3), postimplementation (eFigure in the Supplement). ${ }^{27}$

Regulatory approvals were obtained from the state of Arizona. The University of Arizona institutional review board and Arizona Department of Health Services human subjects review board approved the project and the publication of deidentified data. ${ }^{27-30}$ The institutional review board exempted this project from informed consent, by virtue of being an official, state-vetted public health initiative. While not a clinical trial, EPIC is registered at ClinicalTrials.gov (NCT01339702).

\section{Data Collection}

The Arizona State Trauma Registry contains extensive data on patients taken to level I trauma centers (TCs). Information from included patients (January 1, 2007, to June 30, 2015) was linked to EMS data by accessing paper-based or electronic records from participating agencies, creating a comprehensive prehospital/TC database ${ }^{27}$ (eTables 1 and 2 in the Supplement).

\section{Participants}

Inclusion criteria were adults/children with physical trauma who (1) were transported directly or transferred to a TC by participating agencies, (2) had hospital diagnoses consistent with TBI (isolated or multisystem), and (3) met at least 1 of the following definitions for major TBI: US Centers for Disease Control and Prevention Barell Matrix-Type 1 (eTable 3 in the Supplement) $)^{31-33}$ and/or Abbreviated Injury Scale-Head of at least 3. To prevent selection bias, all patients meeting criteria were included regardless of whether EMS data were obtained. ${ }^{34,35}$

\section{Key Points}

Question Is implementation of prehospital TBI treatment guidelines in demographically diverse emergency medical services systems associated with survival in patients with major traumatic brain injury (TBI)?

Findings In this cohort study, among 21852 patients with moderate, severe, or critical TBI (15228 preimplementation and 6624 postimplementation), guideline implementation was not associated with improved adjusted survival. However, it was associated with improved outcome in the severe and severe, intubated subgroups.

Meaning Statewide implementation of the prehospital TBI guidelines was independently associated with improvement in survival among patients with severe TBI and in the severe, intubated group; these findings support the widespread implementation of the prehospital TBI treatment guidelines.

\section{Interventions}

All Arizona EMS agencies were invited to participate. Program requirements included: EMS TBI guideline training (trainthe-trainer strategy ${ }^{27}$ ); implementing systemwide, guidelinebased treatment (eTables 4-7 in the Supplement) ${ }^{27}$; and providing prehospital data. Training emphasized guideline use in patients with physical trauma, reported/apparent loss of consciousness, and injury sufficient to warrant transport to a hospital. ${ }^{27}$

The guideline-based clinical protocols and algorithms (eTables 4-7 in the Supplement) ${ }^{27}$ focused on 4 interventions: (1) prevention/treatment of hypoxia through early oxygen administration; (2) airway interventions to optimize oxygenation/ventilation (bag-valve-mask [BVM] for airway/ ventilatory compromise and endotracheal intubation [ETI] and extraglottic/supraglottic airways reserved for patients with Glasgow Coma Scale score $<9$ when basic airway interventions were inadequate); (3) prevention of hyperventilation by using age-appropriate ventilation rates and ventilation adjuncts ${ }^{27}$; and (4) avoidance and treatment of hypotension by infusing isotonic fluids. ${ }^{27}$ Primary outcome was survival to hospital discharge (survival), and the secondary outcome was survival to hospital admission (SHA).

\section{Statistical Analysis}

Continuous variables were summarized by median and interquartile range (IQR) and were compared between 2 groups using the Wilcoxon rank sum test. Categorical variables were summarized by frequency and proportion (with 95\% ClopperPearson confidence intervals) and were compared between 2 groups by $x^{2}$ or Fisher exact test.

The primary analysis of risk-adjusted association between survival and intervention was examined by logistic regression, adjusting for important risk factors and potential confounders (see eTable 8 in the Supplement for rationale for choosing the covariates). ${ }^{28-30}$ Sensitivity analysis was performed incorporating the physiologic measures in the Trauma Injury and Injury Severity Score methodology. The effect of age (continuous variable) was fitted nonparametrically using 
penalized thin plate regression splines through the generalized additive model. ${ }^{36}$ The same procedure used for survival was used to model SHA. Fitted models were assessed by deviance residual plots, and area under the receiver operating characteristic curve, with 95\% confidence intervals, was obtained by the DeLong method.

In the secondary analyses (ie, moderate/severe/critical severity-based cohorts and intubated subgroup), standard logistic regression was used when there were at least 200 patients with the outcome and 200 without. Otherwise, the Firth penalized-likelihood logistic regression was used. ${ }^{37,38} \mathrm{Col}$ linearity was checked using variance inflation factors for the parametric terms and concurvity for the nonparametric term. Mixed-effect models for survival/SHA were used to assess the effect of potential correlation of patients treated by the same EMS agency.

In a sensitivity analysis, a propensity score (the probability of being in P3 vs P1) was estimated by logistic regression using all covariates from the final models for outcomes. The propensity score was then included as either linear or smooth function predictors to evaluate the change in adjusted odds ratio (aOR) estimates of intervention for survival and SHA. In secondary analyses, the absolute change in event rates for the same patient at 2 different times (eg, prehospital vs emergency department hypoxia rates) was compared between P1 and P3 by fitting generalized estimating equation models for binary outcome with identity link and exchangeable working correlation matrix and testing an interaction term between time and study phase.

We evaluated secular trends in TBI outcomes in 2 groups of patients brought to the TCs that met study diagnostic criteria but were not eligible for study inclusion: those cared for solely by EMS agencies not participating in EPIC training and those brought to TCs by privately owned vehicle (ie, not affected by EMS care).

We used software environment $\mathrm{R}$ for the analysis ${ }^{39}$ (The R Foundation; packages mgcv, ${ }^{36}$ gamm $4,{ }^{40}$ gee,${ }^{41}$ and logistf ${ }^{42}$ for regression models). All tests were 2 -sided, with $a=.05$, except for the primary analysis, which was .04 (1 interim analysis was conducted with $a=.01$ ).

\section{Results}

\section{Enrollment}

Phase 1 began for all agencies on January 1, 2007. Phase 2 began and ended at different times for each agency (the first agency began training on February 22, 2012, and the last agency completed training on January 23, 2015). Phase 3 ended for all agencies on June 30, 2015. Total enrollment was 26873 , and 5021 were excluded, leaving 21852 (88\% of estimated sample size) for analysis (15228 patients in the preintervention phase [P1 control group] and 6624 patients in the postintervention phase [P3 intervention group]; Figure 1).

Treatment and Treatment-Related Physiologic Changes Training was associated with changes in treatment and treatment-related physiology. The rate of patients having at least 1

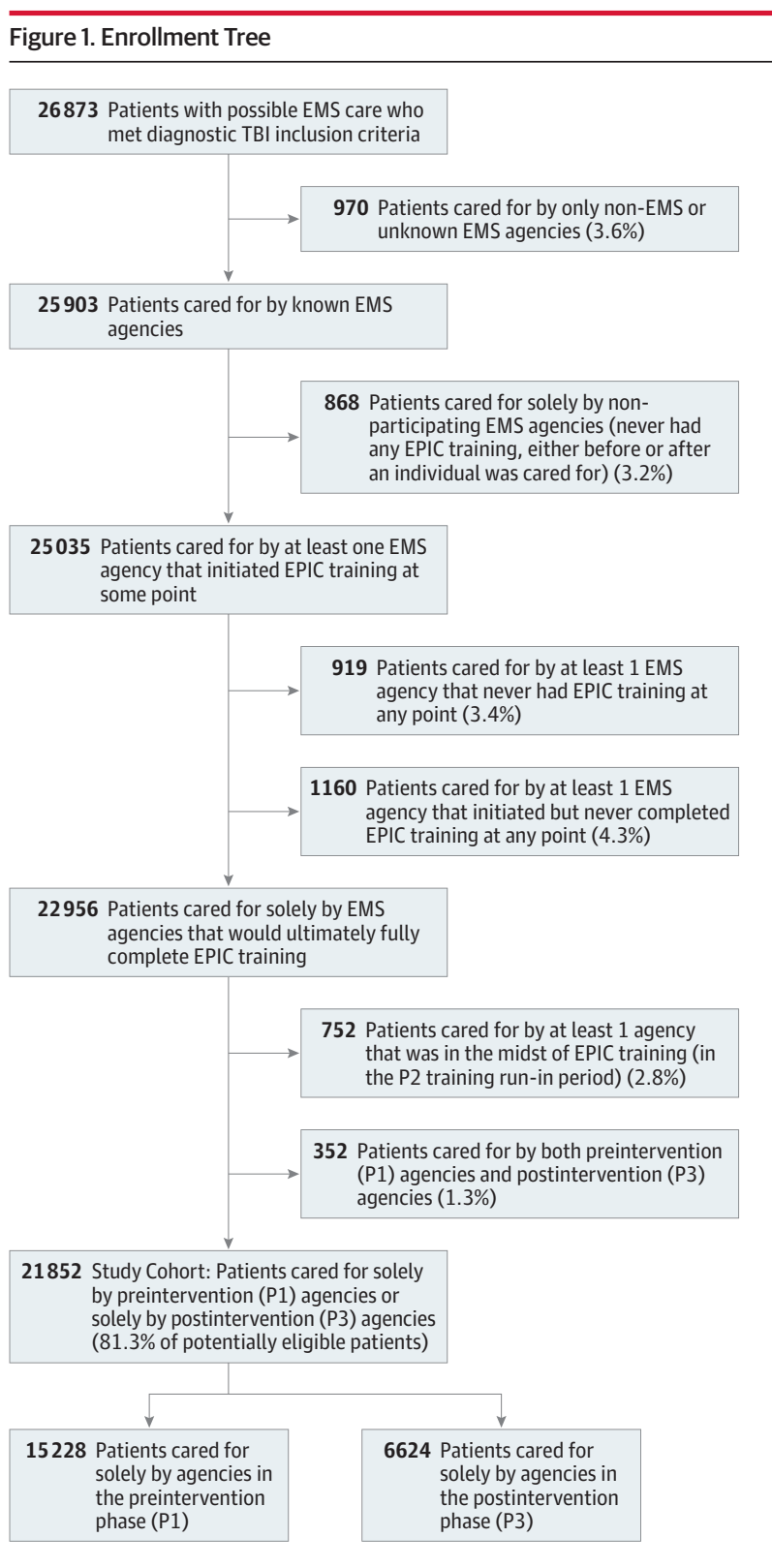

EMS indicates emergency medical services; EPIC, Excellence In Prehospital Injury Care study; P1, study phase 1 (preimplementation phase); P2, study phase 2 (training run-in phase; for each EMS agency, time from initiation to completion of training); $\mathrm{P} 3$, study phase 3 (postimplementation phase); TBI, traumatic brain injury.

EMS oxygen saturation value of $100 \%$ increased significantly after implementation (P1\%, 4823 of 13552 [35.6\%]; P3\%, 2513 of 6141 [40.9\%]; $P<.001$; intubated cohort: P1\%, 985 of 2226 [44.2\%]; P3\%, 482 of 885 [54.6\%]; $P<.001)$. Among intubated patients, hypoxia decreased after EMS care in both P1 and P3. However, the decrease was significantly greater after guideline implementation, and this association was seen at multiple levels of hypoxia (eTable 9 in the Supplement).

The rates of administering intravenous fluid boluses (eTable 10 in the Supplement) and the volume infused (eTable 11 in the Supplement) increased in P3. In addition, after implementation, patients with hypotension were more 
likely to arrive at the TC with a higher systolic blood pressure (SBP) compared with their prehospital SBP.

The intubation rate decreased significantly after implementation, and the BVM-only rate increased (eTable 12 in the Supplement). Among patients receiving positive-pressure ventilation (PPV), the rate of basic airway use only (BVM) increased (P1, 534 of 3531 [15.1\%]; P3, 325 of 1491 [21.8\%]; $P<$.001). Among intubated patients, the rate of hypocapnia (end-tidal carbon dioxide $<35 \mathrm{~mm} \mathrm{Hg}$, reflecting hyperventilation) decreased significantly after implementation (P1, 899 of 1486 [60.5\%]; P3, 372 of 712 [52.2\%]; $P<.001)$.

\section{Analysis and Outcome}

Table 1 shows patient demographics and clinical characteristics. Median age was higher in P3 (50.5 years; IQR, 27-70 years) than P1 (median, 43 years; IQR, 23-63.5 years; $P<.001$ ). The proportion of older patients (by multiple definitions) was much higher in P3 (eTable 13 in the Supplement).

Brain injury severity was greater in P3 (Regional Severity Score-Head [RSS-H] of $4: 2419$ of 6624 [36.5\%; P3] vs 4585 of 15228 [30.1\%; P1]; RSS-H of 5-6, 1492 of 6624 [22.5\%; P3] vs 2952 of 15228 [19.4\%; P1]; $P<.001$ ). This was also true of overall injury severity (Injury Severity Score [ISS] of 16-24, 2411 of 6624 [36.4\%; P3] vs 4863 of 15228 [31.9\%; P1]; $P$ < .001; ISS $\geq 25,2148$ of 6624 [32.4\%; P3] vs 4597 of 15228 [30.2\%; P1]; $P<$.001). Patients in P3 were also more likely to receive prehospital cardiopulmonary resuscitation $(4.4 \%$; 294 of 6624) than those in P1 (3.7\%; 570 of 15 228; $P=.02$; Table 1).

The overall preimplementation/postimplementation analysis revealed an aOR of 1.06 (95\% CI, 0.93-1.21; $P=.40$; Table 2) for survival and 1.70 (95\% CI, 1.38-2.09; $P<.001)$ for SHA (eTable 14 in the Supplement). Sensitivity analyses incorporating random EMS agency effects in the models for survival and SHA yielded only minimal changes in the estimated intervention effects (aOR, 1.04; 95\% CI, 0.91-1.19 and aOR, 1.73; 95\% CI, 1.40-2.13, respectively; eTables 15 and 16 in the Supplement). Sensitivity analyses incorporating the physiologic components of Trauma Injury and Injury Severity Score methodology in the models for survival and SHA also resulted in inconsequential changes (SBP: aOR, 1.06; 95\% CI, 0.93-1.21 and aOR, 1.76; 95\% CI, 1.39-2.21; GCS: aOR, 1.01; 95\% CI, 0.87-1.16 and aOR, 1.63; 95\% CI, 1.32-2.01; respiratory rate: aOR, 1.04 95\% CI, 0.91-1.18 and aOR, 1.79; 95\% CI, 1.43-2.22; eTables 17-22 in the Supplement). Sensitivity analyses that included the propensity score in the models yielded minimal changes (linear predictor: change in aOR survival, $0.47 \%$; SHA, 0.42\%; smooth function survival, $0.89 \%$; SHA, 0.42\%).

The results of the severity-based cohort analyses (moderate: RSS-H 1-2 or ISS 1-14; severe: RSS-H 3-4 or ISS 16-24; and critical: RSS-H 5-6 or ISS 25-75) are shown in Figure 2. The severe subgroups (both TBI-specific and overall injury) showed positive and significant improvement in survival after guideline implementation, while the moderate and critical groups did not. Increases in SHA were most pronounced in the severe TBI group but also occurred in the critical cohort (Figure 2).

The outcomes associated with airway interventions are shown in Figure 3. Patients with severe injury who received any method of PPV (BVM, supraglottic/extraglottic airway, or intubation) and the severe, intubated subgroup showed marked survival improvement after implementation. The criticalinjury subgroups yielded conflicting results, showing either no significant change (overall injury, ISS $\geq 25$ ) or a small negative change in survival (brain injury, RSS-H 5/6).

\section{Discussion}

The EMS TBI guidelines emphasize prevention and treatment of hypoxia, hypotension, and hyperventilation. ${ }^{11}$ These recommendations are based on observational studies demonstrating increased TBI mortality from these insults (hypoxia, ${ }^{14,43-50}$ hypotension, ${ }^{13,14,44,45,47,49-57}$ and hyperventilation ${ }^{11,14,46,58-66}$ ). However, the supporting evidence remains weak because to our knowledge, no controlled prehospital studies have directly evaluated the association of guideline-based care with survival. ${ }^{11,12}$

The EPIC study is a statewide public health initiative implementing the prehospital TBI guidelines ${ }^{10-12,15}$ among patients who experienced injury-associated loss of consciousness. This inclusive approach to guideline implementation at the individual patient level was taken because TBI can be difficult to identify in the field, and its severity may not be immediately apparent. ${ }^{10-12,15,67-72}$

We used an intention-to-treat design because we expected participation from more than 100 EMS agencies and could not guarantee access to prehospital records. ${ }^{35,73}$ Nonetheless, we achieved a $98.7 \%$ linkage rate (ie, EMS data linked to TC data), and eTables 9 to 12 in the Supplement provide evidence that guideline-based treatment increased significantly. As expected in a large implementation effort, there was incomplete application of the guidelines at the individual patient/personnel level (eTables 9-12 in the Supplement). However, there is reason for optimism if future innovations in training and technology can improve guideline compliance (eg, realtime physiologic audiovisual feedback).

The primary analysis (across the entire moderate-to-critical severity spectrum) revealed an aOR of 1.70 (95\% CI, 1.38-2.09; $P<.001)$ for survival to admission. However, the overall aOR of 1.06 (95\% CI, 0.93-1.21) for survival to discharge was nonsignificant $(P=.40)$. The increase in SHA is important because this outcome is proximate to the intervention and likely reflects changes in EMS care. Early outcomes have been recognized to have value for evaluating the effect of prehospital interventions in other serious, time-sensitive conditions. ${ }^{74-78}$ In addition, improved early survival creates the potential for patients to benefit from subsequent specialized care. ${ }^{76,77,79-81}$

We chose broad inclusion criteria because it is not known which severity subgroups benefit from treatment. . $^{3,4,6-11,67,71,72,82}$ This approach prevented unknowingly excluding patients who might benefit (if we made the criteria too narrow). However, it had the risk of diluting the treatment effect (by including nonresponding cohorts). Thus, we planned (a priori) to evaluate the moderate, severe, and critical cohorts separately to prevent some subgroups from potentially hiding the effectiveness of others. Indeed, this approach identified that implementation was strongly associated with improved survival in the severe 


\begin{tabular}{|c|c|c|c|c|}
\hline \multirow[b]{2}{*}{ Characteristic } & \multicolumn{3}{|l|}{ No. (\%) } & \multirow[b]{2}{*}{$P$ Value $^{\mathrm{c}}$} \\
\hline & All $(\mathrm{N}=21852)^{\mathrm{b}}$ & $\mathrm{P} 1(\mathrm{n}=15228)^{b}$ & P3 $(n=6624)^{b}$ & \\
\hline Age, median (IQR), y & $45(24-66)$ & $43(23-63.5)$ & $50.5(27-70)$ & $<.001$ \\
\hline \multicolumn{5}{|l|}{ Male } \\
\hline No & $7181(32.9)$ & $4940(32.4)$ & $2241(33.8)$ & \multirow{3}{*}{.048} \\
\hline Yes & $14666(67.1)$ & $10283(67.5)$ & $4383(66.2)$ & \\
\hline Unknown & 5 & 5 & 0 & \\
\hline \multicolumn{5}{|l|}{ Race/ethnicity } \\
\hline Black & $743(3.4)$ & $506(3.3)$ & $237(3.6)$ & \multirow{6}{*}{.16} \\
\hline Asian & $237(1.1)$ & $151(1)$ & $86(1.3)$ & \\
\hline American Indian/Alaska native & $1400(6.4)$ & $973(6.4)$ & $427(6.4)$ & \\
\hline White & $16408(75.1)$ & $11454(75.2)$ & $4954(74.8)$ & \\
\hline Other & $2791(12.8)$ & $1976(13)$ & $815(12.3)$ & \\
\hline Unknown & $273(1.2)$ & $168(1.1)$ & $105(1.6)$ & \\
\hline \multicolumn{5}{|l|}{ Hispanic } \\
\hline No & $16488(75.5)$ & $11276(74)$ & $5212(78.7)$ & \multirow{3}{*}{$<.001$} \\
\hline Yes & $4719(21.6)$ & $3405(22.4)$ & $1314(19.8)$ & \\
\hline Unknown & $645(3)$ & $547(3.6)$ & $98(1.5)$ & \\
\hline \multicolumn{5}{|l|}{ Payer } \\
\hline Private & $7109(32.5)$ & $5035(33.1)$ & $2074(31.3)$ & \multirow{6}{*}{$<.001$} \\
\hline AHCCCS/Medicaid & $5378(24.6)$ & $3920(25.7)$ & $1458(22)$ & \\
\hline Medicare & $4901(22.4)$ & $3081(20.2)$ & $1820(27.5)$ & \\
\hline Self pay & 3119 (14.3) & $2144(14.1)$ & $975(14.7)$ & \\
\hline Other & $910(4.2)$ & $648(4.3)$ & $262(4)$ & \\
\hline Unknown & $435(2)$ & $400(2.6)$ & $35(0.5)$ & \\
\hline \multicolumn{5}{|l|}{ Trauma type } \\
\hline Blunt & $20794(95.2)$ & $14504(95.2)$ & $6290(95)$ & \multirow{4}{*}{.01} \\
\hline Penetrating & $1053(4.8)$ & $723(4.7)$ & $330(5)$ & \\
\hline Burn & $4(0)$ & 0 & $4(0.1)$ & \\
\hline Unknown & $1(0)$ & $1(0)$ & 0 & \\
\hline \multicolumn{5}{|c|}{ Regional Severity Score-Head (ICD-9) } \\
\hline 1 to 3 & $10233(46.8)$ & $7563(49.7)$ & $2670(40.3)$ & \multirow{4}{*}{$<.001$} \\
\hline 4 & $7004(32.1)$ & $4585(30.1)$ & $2419(36.5)$ & \\
\hline 5 to 6 & $4444(20.3)$ & $2952(19.4)$ & $1492(22.5)$ & \\
\hline Unknown & $171(0.8)$ & $128(0.8)$ & $43(0.6)$ & \\
\hline \multicolumn{5}{|l|}{ Injury Severity score (ICD-9) } \\
\hline 1 to 14 & $7826(35.8)$ & $5765(37.9)$ & $2061(31.1)$ & \multirow{4}{*}{$<.001$} \\
\hline 16 to 24 & $7274(33.3)$ & $4863(31.9)$ & $2411(36.4)$ & \\
\hline$\geq 25$ & 6745 (30.9) & $4597(30.2)$ & $2148(32.4)$ & \\
\hline Unknown & $7(0)$ & $3(0)$ & $4(0)$ & \\
\hline \multicolumn{5}{|l|}{ Body region } \\
\hline Isolated TBI & $16663(76.3)$ & $11602(76.2)$ & $5061(76.4)$ & \multirow{2}{*}{.74} \\
\hline Multisystem TBI & $5189(23.7)$ & $3626(23.8)$ & $1563(23.6)$ & \\
\hline \multicolumn{5}{|l|}{ Transfer } \\
\hline No & $14671(67.1)$ & $10310(67.7)$ & $4361(65.8)$ & \multirow{3}{*}{$<.001$} \\
\hline Yes & $6646(30.4)$ & $4383(28.8)$ & $2263(34.2)$ & \\
\hline Unknown & $535(2.4)$ & $535(3.5)$ & 0 & \\
\hline \multicolumn{5}{|l|}{ CPR } \\
\hline No & 20988 (96) & $14658(96.3)$ & $6330(95.6)$ & \\
\hline Yes & $864(4)$ & $570(3.7)$ & $294(4.4)$ & .02 \\
\hline
\end{tabular}




\begin{tabular}{|c|c|c|c|c|}
\hline \multirow[b]{2}{*}{ Characteristic } & \multicolumn{3}{|l|}{ №. (\%) } & \multirow[b]{2}{*}{$P$ Value $^{c}$} \\
\hline & All $(\mathrm{N}=21852)^{\mathrm{b}}$ & $\mathrm{P} 1(\mathrm{n}=15228)^{\mathrm{b}}$ & P3 $(n=6624)^{b}$ & \\
\hline \multicolumn{5}{|c|}{ Airway management } \\
\hline No PPV & $16830(77)$ & $11697(76.8)$ & $5133(77.5)$ & \multirow{4}{*}{$<.001$} \\
\hline BVM & $859(3.9)$ & $534(3.5)$ & $325(4.9)$ & \\
\hline SGA & $149(0.7)$ & $81(0.5)$ & $68(1)$ & \\
\hline Intubation & $4014(18.4)$ & $2916(19.1)$ & $1098(16.6)$ & \\
\hline \multicolumn{5}{|c|}{ Survival to discharge } \\
\hline No & $3036(13.9)$ & $2036(13.4)$ & $1000(15.1)$ & \multirow{2}{*}{$<.001$} \\
\hline Yes & $18816(86.1)$ & $13192(86.6)$ & $5624(84.9)$ & \\
\hline \multicolumn{5}{|c|}{ Survival to hospital admission } \\
\hline No & $1018(4.7)$ & $723(4.7)$ & $295(4.5)$ & \multirow{2}{*}{.36} \\
\hline Yes & $20834(95.3)$ & $14505(95.3)$ & $6329(95.5)$ & \\
\hline
\end{tabular}

Abbreviations: AHCCCS, Arizona Health Care Cost Containment System; BVM, bag-valve mask (basic airway providing positive-pressure ventilation); CPR, cardiopulmonary resuscitation; ICD-9, International Classification of Diseases, Ninth Revision; IQR, interquartile range; isolated TBI, patients who met TBI inclusion criteria but had no injury with Regional Severity Score of at least 3 in any other (nonhead) body region; multisystem TBI, patients who met TBI inclusion criteria and also had at least 1 nonhead region injury with Regional Severity Score of at least 3; PPV, positive-pressure ventilation (patients received active ventilation regardless of basic or advanced airway type); P1, study phase 1 (preimplementation); P3, study phase 3 (postimplementation); SGA, supraglottic airway (eg, Laryngeal Mask Airway or King Airway); TBI, traumatic brain injury.

${ }^{a}$ Treating trauma center was also highly significant. To protect the mandated anonymity of the participating hospitals, the numbers are not shown (preventing any possible identification or inference of facility-specific outcome differences).

${ }^{\mathrm{b}}$ Median (IQR) for numerical variables and count (percentage) for categorical variables

${ }^{c}$ Fisher exact test or $\chi^{2}$ test, as appropriate, for categorical variables and Wilcoxon rank sum test for continuous variables; the unknown category, if present, is excluded from the testing procedure.

subgroups (RSS-H 3-4: aOR, 2.03; 95\% CI, 1.52-2.72; $P<.001$; ISS 16-24: aOR, 1.61; 95\% CI, 1.07-2.48; $P$ = .02; Figure 2).

These findings support a concept of an interventional sweet spot between the extremes of TBI severity. At the moderate end of the spectrum, detecting differences in mortality is unlikely owing to the low death rate. But in critical TBI, even optimal treatment may have little effect on survival. In contrast, the severe group may benefit far more from the prevention of secondary insults than patients who have devastating primary injury and whose mortality risk is high regardless of treatment. Indeed, the effect of hypoxia and hypotension on survival was significantly greater in patients with severe injury than those with critical injury. Both of these secondary insults were associated with lower odds of survival among the patients with RSS-H of 3 or 4 (hypoxia OR, 0.181; 95\% CI, 0.137-0.243; hypotension OR, 0.193; 95\% CI, 0.146-0.258) than in those with RSS-H of 5-6 (hypoxia OR, 0.262 ; 95\% CI, 0.220-0.313; $P=.03$ for the difference; hypotension OR, 0.280; 95\% CI, 0.229-0.342; $P=.03$ ). Hence, the relative association of primary vs secondary injury with survival may vary with severity, with primary injury being the main determiner of outcome in critical patients and secondary injury taking on more significance in patients with less severe injuries, where the initial insult leaves greater potential for improvement or deterioration. It is notable that other TBI studies have focused on the middle-severity cohort as well. . $^{3,9,72,83-85}$

The lack of treatment effect in critical patients may not be solely owing to irreversible pathoanatomic injury. Rather, variations in severity-associated physiologic response may also play a role. For instance, while the rate of intubated patients with at least 1 oxygen saturation of $100 \%$ increased significantly after implementation (P1, 985 of 2226 [44.2\%] vs P3\%, 482 of 885 [54.6\%]; $P<.001)$. This increase varied dramatically with severity. In the severe group (RSS-H 3-4), the rate increased from $50.7 \%$ (491 of 968 ; P1) to $66.9 \%$ (216 of 323; P3) (16.2\% absolute increase). However, in the critical cohort (RSS-H 5-6), the increase was only 7.1\% (39.4\% [463 of 1176] to $46.5 \%$ [252 of 542]; $P=.02$ for the difference between the severe and critical subgroups ). Furthermore, the patients with hypotension and severe injury in P3 were less than half as likely to arrive at the TC with a further drop in SBP $(2.0 \%)$ than those in P1 $(5.1 \%, P=.048)$. In contrast, the hypotensive, critical cohorts in $\mathrm{P} 3$ and $\mathrm{P} 1$ had a similar likelihood of experiencing an additional SBP drop on arrival (P3 = 8.5\%; P1 = 10.7\%; $P=.49$ ). These findings support the concept that physiologic improvement may be more difficult to achieve in critical patients.

The lack of improvement in the highest-severity cohort is not surprising and may be due to the Stocchetti effect. ${ }^{83,86} \mathrm{Im}-$ provements in prehospital trauma care may lead to a paradoxical effect of improved prehospital survival but decreased hospital survival because critical patients who previously died in the field may survive to hospital admission but die in hospital from extremely severe injury. ${ }^{83,86}$ We believe that the postimplementation increases in SHA in the

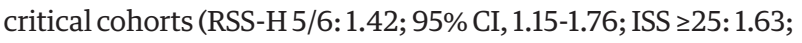
95\% CI, 1.32-2.00; Figures 2 and 3), the larger proportion of older patients (eTable 13 in the Supplement), and the higher rate of patients receiving prehospital CPR (Table 1) all support the interpretation that the Stocchetti Effect explained at least part of the lack of improvement in the critical cohort. 


\begin{tabular}{|c|c|c|}
\hline Variable & OR $(95 \% \mathrm{Cl})$ & $P$ Value \\
\hline Intervention & $1.06(0.929-1.21)$ & .40 \\
\hline \multicolumn{3}{|l|}{ Male } \\
\hline No & 1 [Reference] & \multirow{2}{*}{.74} \\
\hline Yes & $1.02(0.896-1.17)$ & \\
\hline \multicolumn{3}{|l|}{ Race/ethnicity } \\
\hline Black & 1 [Reference] & \multirow{6}{*}{.005} \\
\hline Asian & $0.787(0.417-1.49)$ & \\
\hline American Indian/Alaska native & $0.719(0.476-1.08)$ & \\
\hline White & $0.850(0.611-1.18)$ & \\
\hline Other & $0.678(0.462-0.994)$ & \\
\hline Unknown & $0.382(0.214-0.679)$ & \\
\hline \multicolumn{3}{|l|}{ Hispanic } \\
\hline No & 1 [Reference] & \multirow{3}{*}{.02} \\
\hline Yes & $1.14(0.959-1.36)$ & \\
\hline Unknown & $0.686(0.483-0.974)$ & \\
\hline \multicolumn{3}{|l|}{ Payer } \\
\hline Private & 1 [Reference] & \multirow{6}{*}{$<.001$} \\
\hline AHCCCS/Medicaid & $1.12(0.949-1.33)$ & \\
\hline Medicare & $0.942(0.762-1.17)$ & \\
\hline Self pay & $0.464(0.385-0.559)$ & \\
\hline Other & $0.829(0.619-1.11)$ & \\
\hline Unknown & $0.309(0.210-0.454)$ & \\
\hline \multicolumn{3}{|l|}{ Trauma type } \\
\hline Blunt & 1 [Reference] & \multirow{2}{*}{$<.001$} \\
\hline Penetrating & $0.159(0.130-0.196)$ & \\
\hline \multicolumn{3}{|l|}{ Head Injury Severity score (ICD-9) } \\
\hline 1 to 3 & 1 [Reference] & \multirow{3}{*}{$<.001$} \\
\hline 4 & $0.835(0.649-1.07)$ & \\
\hline 5 to 6 & $0.047(0.036-0.061)$ & \\
\hline \multicolumn{3}{|l|}{ Injury Severity score (ICD-9) } \\
\hline 1 to 14 & 1 [Reference] & \multirow{3}{*}{$<.001$} \\
\hline 16 to 24 & $0.444(0.303-0.649)$ & \\
\hline$\geq 25$ & $0.181(0.122-0.269)$ & \\
\hline \multicolumn{3}{|l|}{ Body region } \\
\hline Isolated TBI & 1 [Reference] & \multirow{2}{*}{$<.001$} \\
\hline Multisystem TBI & $0.488(0.423-0.563)$ & \\
\hline \multicolumn{3}{|l|}{ Transfer } \\
\hline No & 1 [Reference] & \multirow{3}{*}{$<.001$} \\
\hline Yes & $2.12(1.79-2.51)$ & \\
\hline Unknown & $1.25(0.798-1.96)$ & \\
\hline \multicolumn{3}{|l|}{ CPR } \\
\hline No & 1 [Reference] & \multirow{2}{*}{$<.001$} \\
\hline Yes & $0.029(0.021-0.040)$ & \\
\hline Hospital $^{a}$ & Not shown & $<.001$ \\
\hline Age, y & Nonparametric function & $<.001$ \\
\hline
\end{tabular}

Abbreviations, AHCCCS, Arizona Health Care Cost Containment System; CPR, cardiopulmonary resuscitation; ICD-9, International Classification of Diseases, Ninth Revision; isolated TBI, patients who met TBI inclusion criteria but had no injury with Regional Severity Score $\geq 3$ in any other (nonhead) body region; multisystem TBI, patients who met TBI inclusion criteria and also had at least 1 nonhead region injury with Regional Severity Score $\geq 3$; OR, odds ratio.

${ }^{a}$ Hospital (treating trauma center) was also highly significant. To protect the mandated anonymity of the participating hospitals, the numbers are not shown (preventing any possible identification or inference of facility-specific outcome differences)
Prehospital intubation for TBI has been controversial for decades. ${ }^{10-12,15,23,59,64,66,67,87-91}$ However, in studies associating intubation with negative outcomes, ${ }^{23,66,67,88,91}$ it is unclear whether the primary issue was the procedure itself or the high rate of inadvertent hyperventilation following intubation. ${ }^{43,64,65,85,87,92}$ In EPIC, training emphasized the guideline-based approach of reserving intubation for those with markedly depressed level of consciousness and in whom basic interventions were inadequate for airway protection and oxygenation. ${ }^{10-12,15}$ Several findings provide evidence that this approach was implemented. Despite increased severity of both brain and overall injury in P3, the intubation rate decreased and the BVMonly rate increased (eTable 12 in the Supplement). Furthermore, among PPV cases, the rate of BVM-only use increased markedly (relative increase $=44.1 \%, P<.001$ ) .

Postimplementation adjusted survival tripled in the PPV and ETI severe cohorts (both TBI-specific and overall injury; Figure 3). This may be owing to the focus on oxygenation/preoxygenation and preventing hyperventilation via (1) intentional emphasis on achieving target end-tidal carbon dioxide (35-45 mm Hg), (2) the use of ventilation rate timers as real-time visual cues for manual ventilation, and (3) use of flow-controlled ventilation bags. These findings imply that intubation, combined with proper ventilation, may be the optimal approach to prehospital airway management in patients with major TBI who meet the criteria recommended in the guidelines. Clearly, many questions related to this issue require further study.

Two challenges of EPIC were its length (the typical agency participated for 3 years following implementation) and our inability to enforce retraining after initial education. Thus, there was a potential for decreased emphasis on guideline adherence over time. To evaluate this, we assessed temporal changes in outcome by comparing P1 to early P3 (months 1-18) and late P3 ( $\geq 19$ months). There was initial improvement, but the effect faded (aOR for survival: early P3, 1.16; 95\% CI, 0.99-1.37; “late” P3, 0.95; 0.80-1.13). This was also reflected by the interim analysis (accrual: March 31, 2014), which was positive for survival (aOR, 1.16; 95\% CI, 1.00-1.34; $P=.048)$. However, the final analysis reverted (aOR, 1.06; 95\% CI, 0.93-1.21; $P=.40$ ). The reason we did not report a positive study at the interim analysis was because the $P$ value required for early termination was $P$ less than .01. Interestingly, in retrospect, if we had planned the study to only last until the interim analysis, we would have reported a positive study at that time (ie, $P<$.05). We believe these findings reflect the need for focused, recurrent training to help prevent deterioration of guideline adherence over time.

\section{Limitations}

This study has limitations. First, it was not randomized. Although a randomized clinical trial might definitively identify optimal treatment, such a trial was not feasible. Because existing studies overwhelmingly report detrimental effects of hypoxia, hypotension, and hyperventilation, randomization (to treat/not treat) would be unacceptable to most EMS 
Figure 2. Primary Analysis: Adjusted Survival

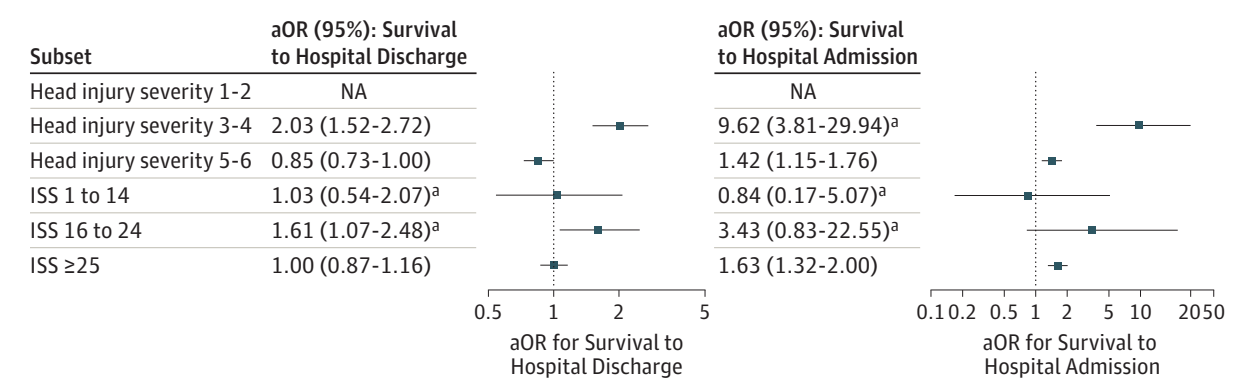

Postintervention adjusted odds of survival to hospital discharge or admission for the moderate (Injury Severity Score [ISS] of 1-14), severe (Regional Severity Score-Head of 3 or 4; ISS of 16-24), and critical (Regional Severity Score-Head of 5 or 6; ISS of 25-75) injury cohorts. Logistic regression was used when there were at least 200 patients with the event (eg, survived to discharge) and 200 without (eg, did not survive to discharge). Number of events/number of subjects in each subgroup: Head Injury Severity 1-2: survival to discharge 2072 of 2090; survival to hospital admission (SHA) 2084 of 2090; Head Injury Severity 3-4: survival to discharge 14754 of 15 147; SHA 15038 of 15 147; Head Injury Severity 5-6: survival to discharge 1885 of 4444; SHA, 3587 of 4444; ISS 1 to 14: survival to discharge, 7757 of 7826; SHA, 7801/7826; ISS 16 to 24: survival to discharge, 7115 of 7274; SHA, 7241/7274; ISS $\geq 25$ : survival to discharge, 3937/6745; SHA, 5785/6745. aOR indicates adjusted odds ratio; NA, not applicable owing to numbers being too small for adjusted analysis.

${ }^{a}$ In comparisons that did not meet the criteria of at least 200 patients with the event and 200 without, Firth penalized-likelihood logistic regression was used.

Figure 3. Adjusted Analysis of Survival and Survival to Hospital Admission by Severity Cohorts in Patients with Positive-Pressure Ventilation (PPV)/Intubation

A Survival by airway/ventilatory intervention

\begin{tabular}{ll} 
Subset & $\begin{array}{l}\text { aOR (95\%): Survival } \\
\text { to Hospital Discharge }\end{array}$ \\
\hline PPV Head injury severity 3-4 & $3.52(1.96-6.34)$ \\
\hline PPV Head injury severity 5-6 & $0.72(0.58-0.88)$ \\
\hline PPV ISS 16 to 24 & $2.75(1.15-7.53)^{\mathrm{a}}$ \\
\hline PPV ISS $\geq 25$ & $0.87(0.72-1.06)$ \\
\hline ETI Head injury severity 3-4 & $3.14(1.65-5.98)$ \\
\hline ETI Head injury severity 5-6 & $0.67(0.52-0.86)$ \\
\hline ETI ISS 16 to 24 & $3.28(1.19-11.34)^{\mathrm{a}}$ \\
\hline ETI ISS $\geq 25$ & $0.81(0.64-1.01)$ \\
\hline & \\
\hline
\end{tabular}

B SHA by airway/ventilatory intervention

\begin{tabular}{lll} 
Subset & $\begin{array}{l}\text { aOR (95\%): Survival } \\
\text { to Hospital Admission }\end{array}$ \\
\hline PPV Head injury severity 3-4 & $6.44(2.39-22.04)^{\mathrm{a}}$ \\
\hline PPV Head injury severity 5-6 & $1.40(1.13-1.75)$ \\
\hline PPV ISS 16 to 24 & $4.57(0.61-94.48)^{\mathrm{a}}$ \\
\hline PPV ISS $\geq 25$ & $1.53(1.23-1.89)$ \\
\hline ETI Head injury severity 3-4 & $4.93(1.75-17.50)^{\mathrm{a}}$ \\
\hline ETI Head injury severity 5-6 & $1.43(1.32-1.84)$ \\
\hline ETI ISS 16 to 24 & $4.89(0.54-173.66)^{\mathrm{a}}$ \\
\hline ETI ISS $\geq 25$ & $1.53(1.20-1.96)$ \\
& & \\
\hline
\end{tabular}

Postintervention adjusted odds of survival to hospital discharge or admission, by airway intervention category, for the severe (Regional Severity Score-Head of 3 or 4; Injury Severity Score [ISS] of 16-24) and critical injury cohorts (Regional Severity Score-Head of 5 or 6; Injury Severity Score of 25-75). The moderate severity category analyses (Regional Severity Score-Head of 1 or 2; ISS of 1-14) are not shown owing to the very small number of deaths in these cohorts, preventing meaningful/stable regression model results. Logistic regression was used when there were at least 200 patients with the event (eg, survived to discharge) and 200 without (eg, did not survive to discharge). For PPV, inclusion criteria were all patients with active ventilation whether basic (bag-valve mask) or advanced airway (supraglottic/extraglottic airway or endotracheal intubation). Number of events/number of subjects in each subgroup: PPV Head Injury Severity 3-4: survival to discharge, 1618 of 1842; SHA 1741 of 1842; PPV Head Injury Severity 5-6: survival to discharge, 771 of 2,992; SHA, 2149 of 2992; PPV ISS 16 to 24: survival to discharge, 751 of 822; SHA, 793 of 822; PPV ISS $\geq 25$ : survival to discharge, 1359/3770; SHA, 2829/3770; endotracheal intubation (ETI) Head Injury Severity 3-4: survival to discharge 1257/1457; SHA 1364/1457; ETI Head Injury Severity 5-6: survival to discharge 603 of 2402; SHA 1689 of 2402; ETI ISS 16 to 24: survival to discharge, 586 of 647; SHA, 620 of 647; ETI ISS $\geq 25$ : survival to discharge, 1055 of 3024; SHA, 2224/3024. aOR indicates adjusted odds ratio.

${ }^{a}$ In comparisons that did not meet the criteria of at least 200 patients with the event and 200 without, Firth penalized-likelihood logistic regression was used.

systems. Use of a pragmatic trial design (eg, stepped-wedge or cluster-randomized) ${ }^{93}$ was also nonfeasible because the timing of EPIC training had to be determined primarily by agency-specific operational factors.

Because the guidelines were implemented as a "bundle," we cannot identify the relative effect of specific interventions (eg, oxygenation/preoxygenation). This would have required stepwise, intervention-specific implementation, and this was not feasible.

To evaluate potential influence of secular trends, we assessed concurrent outcomes in 2 cohorts taken to the TCs that met diagnostic inclusion criteria but were unaffected by EPIC. First, we assessed patients transported by nonparticipating EMS agencies. However, the agency recruitment was so successful that this cohort was much smaller than anticipated (233 total; mean, 27.4 per year). Second, we evaluated patients brought to TCs by privately owned vehicle $(n=1486)$. The before/after analysis (early patients [January 1, 2007, to December 31, 2012] vs late [January 1, 2013 , to June 30, 2015]) yielded no evidence of outcome improvement over time. Indeed, there was a trend toward somewhat worse outcomes in the late group (eTable 23 in 
the Supplement). It is noteworthy that the trauma system in Arizona developed during the 1980s and was very stable during EPIC. The TCs accounting for $98.1 \%$ of patients (21 432 of 21852 ) were established more than a decade before the study began.

Finally, we could not control for the effects of inpatient care. Thus, we cannot know conclusively that the improvements were directly caused by EMS guideline implementation. However, the concurrent increase in survival to hospital admission (aOR, 1.70; 95\% CI, 1.38-2.09; $P<$.001) is supportive of the conclusion that EMS implementation was associated with the improvements in outcome.

\section{Conclusions}

Statewide implementation of the prehospital TBI guidelines was not associated with improved overall survival (across the entire, combined moderate to critical spectrum). However, survival doubled among patients with severe TBI and tripled in the patients with severe TBI who received PPV and/or intubation. Implementation was also independently associated with significant improvement in survival to hospital admission. These findings support the widespread implementation of the prehospital TBI treatment guidelines.

\section{ARTICLE INFORMATION}

Accepted for Publication: March 3, 2019.

Published Online: May 8, 2019.

doi:10.1001/jamasurg.2019.1152

Author Affiliations: Arizona Emergency Medicine Research Center, College of Medicine, The University of Arizona, Phoenix (Spaite, Bobrow, Keim, Barnhart, Gaither, Denninghoff, Rice, Viscusi, $\mathrm{Hu})$; Department of Emergency Medicine, College of Medicine, The University of Arizona, Tucson (Spaite, Bobrow, Keim, Gaither, Denninghoff, Rice, Viscusi); Arizona Department of Health Services, Bureau of EMS, Phoenix, Arizona (Bobrow, Chikani, Mullins); Mel and Enid Zuckerman College of Public Health, The University of Arizona, Tucson (Keim, Sherrill, Hu); Barrow Neurological Institute at Phoenix Children's Hospital, Department of Child Health/Neurosurgery, College of Medicine, The University of Arizona, Phoenix (Adelson).

Author Contributions: Drs Spaite and Hu had full access to all the data in the study and take responsibility for the integrity of the data and the accuracy of the data analysis.

Concept and design: Spaite, Keim, Gaither, Denninghoff.

Acquisition, analysis, or interpretation of data: All authors.

Drafting of the manuscript: Spaite, Keim, Chikani, $\mathrm{Hu}$

Critical revision of the manuscript for important intellectual content: Spaite, Bobrow, Keim, Barnhart, Gaither, Sherrill, Denninghoff, Mullins, Adelson, Rice, Viscusi, Hu.

Statistical analysis: Keim, Chikani, Sherrill, Hu. Obtained funding: Spaite, Keim, Denninghoff. Administrative, technical, or material support: Spaite, Keim, Barnhart, Gaither, Mullins, Viscusi. Supervision: Spaite, Bobrow, Barnhart, Mullins, Adelson.

Conflict of Interest Disclosures: Drs Spaite, Bobrow, Barnhart, Chikani, Gaither, Sherrill, Adelson, Viscusi, and Hu received support from the $\mathrm{NIH}$ grant via their university/academic appointments.

Funding/Support: The EPIC Study is funded by a grant from the National Institutes of Health (1R01NS071049)

Role of the Funder/Sponsor: The funding source had no role in the design and conduct of the study; collection, management, analysis, and interpretation of the data; preparation, review, or approval of the manuscript; and decision to submit the
Disclaimer: The content is solely the responsibility of the authors and does not necessarily represent the official views of the National Institutes of Health.

Additional Contributions: We thank the more than 11000 emergency medical systems practitioners, 134 Fire Departments and EMS agencies, and all of the Level I Trauma Centers throughout Arizona. Without these dedicated professionals and organizations, the EPIC Project would not have been possible.

\section{REFERENCES}

1. Bell JMBM, Jenkins EL, Haarbauer-Krupa J. Traumatic Brain Injury In the United States: Epidemiology and Rehabilitation. Washington, DC: National Center for Injury Prevention and Control, Division of Unintentional Injury Prevention, Centers for Disease Control; 2014

2. Finkelstein $\mathrm{E}$, Corso PS, Miller TR. The Incidence and Economic Burden of Injuries in the United States. New York, NY: Oxford University Press; 2006. doi: 10.1093/acprof:oso/9780195179484.001.0001

3. Wright DW, Yeatts SD, Silbergleit R, et al; NETT Investigators. Very early administration of progesterone for acute traumatic brain injury. NEngl J Med. 2014;371(26):2457-2466. doi:10. 1056/NEJMoa1404304

4. Maas Al, Steyerberg EW, Marmarou A, et al IMPACT recommendations for improving the design and analysis of clinical trials in moderate to severe traumatic brain injury. Neurotherapeutics. 2010;7 (1):127-134. doi:10.1016/j.nurt.2009.10.020

5. Maas Al, Marmarou A, Murray GD, Teasdale SG Steyerberg EW. Prognosis and clinical trial design in traumatic brain injury: the IMPACT study. J Neurotrauma. 2007;24(2):232-238. doi:10.1089/ neu.2006.0024

6. Doppenberg EM, Choi SC, Bullock R. Clinical trials in traumatic brain injury: lessons for the future. J Neurosurg Anesthesiol. 2004;16(1):87-94. doi:10.1097/00008506-200401000-00019

7. Loane DJ, Faden AI. Neuroprotection for traumatic brain injury: translational challenges and emerging therapeutic strategies. Trends Pharmacol Sci. 2010;31(12):596-604. doi:10.1016/j.tips.2010. 09.005

8. Saatman KE, Duhaime AC, Bullock R, Maas AI Valadka A, Manley GT; Workshop Scientific Team and Advisory Panel Members. Classification of traumatic brain injury for targeted therapies. J Neurotrauma. 2008;25(7):719-738. doi:10.1089/ neu.2008.0586
9. Marshall LF. Head injury: recent past, present and future. Neurosurgery. 2000;47(3):546-561.

10. Brain Trauma F; American Association of Neurological S; Congress of Neurological S. Guidelines for the management of severe traumatic brain injury. J Neurotrauma. 2007;24(suppl 1):S1S106

11. Badjatia N, Carney N, Crocco TJ, et al; Brain Trauma Foundation; BTF Center for Guidelines Management. Guidelines for prehospital management of traumatic brain injury 2nd edition. Prehosp Emerg Care. 2008;12(suppl 1):S1-S52. doi: 10.1080/10903120701732052

12. Kochanek PM, Carney N, Adelson PD, et al; American Academy of Pediatrics-Section on Neurological Surgery; American Association of Neurological Surgeons/Congress of Neurological Surgeons; Child Neurology Society; European Society of Pediatric and Neonatal Intensive Care; Neurocritical Care Society; Pediatric Neurocritical Care Research Group; Society of Critical Care Medicine; Paediatric Intensive Care Society UK; Society for Neuroscience in Anesthesiology and Critical Care; World Federation of Pediatric Intensive and Critical Care Societies. Guidelines for the acute medical management of severe traumatic brain injury in infants, children, and adolescents: second edition. Pediatr Crit Care Med. 2012;13(supp 1):S1-S82. doi:10.1097/PCC.Ob013e318259ee85

13. Jankowitz BT, Adelson PD. Pediatric traumatic brain injury: past, present and future. Dev Neurosci. 2006;28(4-5):264-275. doi:10.1159/000094153

14. Chesnut RM, Marshall LF, Klauber MR, et al. The role of secondary brain injury in determining outcome from severe head injury. J Trauma. 1993; 34(2):216-222. doi:10.1097/00005373-199302000 00006

15. Adelson PD, Bratton SL, Carney NA, et al: American Association for Surgery of Trauma; Child Neurology Society; International Society for Pediatric Neurosurgery; International Trauma Anesthesia and Critical Care Society; Society of Critical Care Medicine; World Federation of Pediatric Intensive and Critical Care Societies. Guidelines for the acute medical management of severe traumatic brain injury in infants, children, and adolescents, chapter 1: introduction. Pediatr Crit Care Med. 2003;4(3)(suppl):S2-S4. doi:10. 1097/01.CCM.0000066600.71233.01

16. Faul M, Wald MM, Rutland-Brown W, Sullivent $E E$, Sattin RW. Using a cost-benefit analysis to estimate outcomes of a clinical treatment guideline: testing the Brain Trauma Foundation guidelines for the treatment of severe traumatic brain injury. 
J Trauma. 2007;63(6):1271-1278. doi:10.1097/TA. Ob013e3181493080

17. Fakhry SM, Trask AL, Waller MA, Watts DD, Force INT; IRTC Neurotrauma Task Force. Management of brain-injured patients by an evidence-based medicine protocol improves outcomes and decreases hospital charges. J Trauma. 2004;56(3):492-499. doi:10.1097/01.TA 0000115650.07193 .66

18. Palmer S, Bader MK, Qureshi A, et al; Americans Associations for Neurologic Surgeons. The impact on outcomes in a community hospital setting of using the AANS traumatic brain injury guidelines. J Trauma. 2001;50(4):657-664. doi:10.1097/ 00005373-200104000-00010

19. Kreutzer JS, Kolakowsky-Hayner SA, Ripley D, et al. Charges and lengths of stay for acute and inpatient rehabilitation treatment of traumatic brain injury 1990-1996. Brain Inj. 2001;15(9):763-774 doi:10.1080/02699050010025786

20. Vavilala MS, Kernic MA, Wang J, et al; Pediatric Guideline Adherence and Outcomes Study. Acute care clinical indicators associated with discharge outcomes in children with severe traumatic brain injury. Crit Care Med. 2014;42(10):2258-2266. doi: 10.1097/CCM.0000000000000507

21. O'Lynnger TM, Shannon CN, Le TM, et al. Standardizing ICU management of pediatric traumatic brain injury is associated with improved outcomes at discharge. J Neurosurg Pediatr. 2016; 17(1):19-26. doi:10.3171/2015.5.PEDS1544

22. Stiell IG, Spaite DW, Field B, et al; OPALS Study Group. Advanced life support for out-of-hospital respiratory distress. N Engl J Med. 2007;356(21): 2156-2164. doi:10.1056/NEJMoa060334

23. Stiell IG, Nesbitt LP, Pickett W, et al; OPALS Study Group. The OPALS Major Trauma Study: impact of advanced life-support on survival and morbidity. CMAJ. 2008;178(9):1141-1152. doi:10. 1503/cmaj.071154

24. Stiell IG, Wells GA, Field B, et al; Ontario Prehospital Advanced Life Support Study Group. Advanced cardiac life support in out-of-hospital cardiac arrest. N Engl J Med. 2004;351(7):647-656. doi:10.1056/NEJMoa040325

25. Stiell IG, Wells GA, Spaite DW, et al; OPALS Study Group. The Ontario Prehospital Advanced Life Support (OPALS) study part II: rationale and methodology for trauma and respiratory distress patients. Ann Emerg Med. 1999;34(2):256-262. doi: 10.1016/S0196-0644(99)70241-6

26. Spaite DW, Beskind DL, Garrison HG. Evaluating the effectiveness of EMS systems: utilizing outcomes research methods to identify the impact of prehospital care. In: Cone DC, O'Conner RE, Fowler R, eds. Emergency Medical Services: Clinical Practice and Systems Oversight. Overland Park, KS: National Association of EMS Physicians: 2009.

27. Spaite DW, Bobrow BJ, Stolz U, et al. Evaluation of the impact of implementing the emergency medical services traumatic brain injury guidelines in Arizona: the Excellence in Prehospital Injury Care (EPIC) study methodology. Acad Emerg Med. 2014; 21(7):818-830. doi:10.1111/acem.12411

28. Spaite DW, Hu C, Bobrow BJ, et al. Mortality and prehospital blood pressure in patients with major traumatic brain injury: implications for the hypotension threshold. JAMA Surg. 2017;152(4): 360-368. doi:10.1001/jamasurg.2016.4686

29. Spaite DW, Hu C, Bobrow BJ, et al. Association of out-of-hospital hypotension depth and duration with traumatic brain injury mortality. Ann Emerg Med. 2017;70(4):522-530.e1. doi:10.1016/j.annemergmed. 2017.03.027

30. Spaite DW, Hu C, Bobrow BJ, et al. The effect of combined out-of-hospital hypotension and hypoxia on mortality in major traumatic brain injury. Ann Emerg Med. 2017;69(1):62-72. doi:10.1016/j. annemergmed.2016.08.007

31. Barell V, Aharonson-Daniel L, Fingerhut LA, et al. An introduction to the Barell body region by nature of injury diagnosis matrix. Inj Prev. 2002;8 (2):91-96. doi:10.1136/ip.8.2.91

32. Clark DE, Ahmad S. Estimating injury severity using the Barell matrix. Inj Prev. 2006;12(2):111-116. doi:10.1136/ip.2005.010058

33. US Centers for Disease Control and Prevention. Barell matrix CDC website. https://www.cdc.gov/ nchs/injury/injury_matrices.htm. Accessed April 22, 2010.

34. Spaite DW, Criss EA, Valenzuela TD, Guisto J. Emergency medical service systems research: problems of the past, challenges of the future. Ann Emerg Med. 1995;26(2):146-152. doi:10.1016/ S0196-0644(95)70144-3

35. Spaite DW, Valenzuela TD, Meislin HW. Barriers to EMS system evaluation: problems associated with field data collection. Prehosp Disaster Med. 1993;8:S35-S40.

36. Wood SN. Generalized Additive Models: An Introduction with R. 2nd ed. Boca Raton, FL: Chapman and Hall/CRC; 2017. doi:10.1201/9781315370279

37. Firth D. Bias reduction of maximum-likelihoodestimates. Biometrika. 1993;80:27-38. doi:10.1093/ biomet/80.1.27

38. Heinze G, Schemper M. A solution to the problem of separation in logistic regression. Stat Med. 2002;21(16):2409-2419. doi:10.1002/sim.1047

39. R: a language and environment for statistical computing: Version 3.4.4. R Foundation for Statistical Computing. https://www.R-project.org/. Accessed April 26, 2018

40. gamm4: Generalized Additive Mixed Models using 'mgcv' and 'Ime4' (R package version 0.2-5) https://CRAN.R-project.org/package=gamm4. Published 2017. Accessed July 30, 2018

41. gee: Generalized Estimation Equation Solver ( $R$ package version 4.13-19). https://CRAN.R-project. org/package=gee. Accessed May 10, 2018

42. logistf: Firth's Bias-Reduced Logistic Regression (R package version 1.22). https://CRAN.R-project. org/package=logistf. Accessed May 10, 2018.

43. Davis DP, Idris AH, Sise MJ, et al. Early ventilation and outcome in patients with moderate to severe traumatic brain injury. Crit Care Med. 2006;34(4):1202-1208. doi:10.1097/01.CCM. $0000208359.74623 .1 \mathrm{C}$

44. Stocchetti N, Furlan A, Volta F. Hypoxemia and arterial hypotension at the accident scene in head injury. J Trauma. 1996;40(5):764-767. doi:10.1097/ 00005373-199605000-00014

45. Cooke RS, McNicholl BP, Byrnes DP. Early management of severe head injury in Northern Ireland. Injury. 1995;26(6):395-397. doi:10.1016/ 0020-1383(95)00003-R
46. Davis DP, Dunford JV, Poste JC, et al. The impact of hypoxia and hyperventilation on outcome after paramedic rapid sequence intubation of severely head-injured patients. J Trauma. 2004;57 (1):1-8. doi:10.1097/01.TA.0000135503.71684.C8

47. Fearnside MR, Cook RJ, McDougall $P, M c N e i$ RJ. The Westmead Head Injury Project outcome in severe head injury: a comparative analysis of pre-hospital, clinical and CT variables. Br J Neurosurg. 1993;7(3):267-279. doi:10.3109/ 02688699309023809

48. Marmarou A, Anderson RL, Ward JD, et al. Impact of Icp instability and hypotension on outcome in patients with severe head trauma. J Neurosurg. 1991;75:S59-S66. doi:10.3171/sup.1991. 75.1s.0s59

49. Mayer TA, Walker ML. Pediatric head injury: the critical role of the emergency physician. Ann Emerg Med. 1985;14(12):1178-1184. doi:10.1016/SO196 0644(85)81025-8

50. Ong L, Selladurai BM, Dhillon MK, Atan M, Lye MS. The prognostic value of the Glasgow Coma Scale, hypoxia and computerised tomography in outcome prediction of pediatric head injury. Pediatr Neurosurg. 1996;24(6):285-291. doi:10.1159/ 000121057

51. Shutter LA, Narayan RK. Blood pressure management in traumatic brain injury. Ann Emerg Med. 2008;51(3)(suppl):S37-S38. doi:10.1016/j. annemergmed.2007.11.013

52. Gentleman D. Causes and effects of systemic complications among severely head injured patients transferred to a neurosurgical unit. Int Surg. 1992;77(4):297-302.

53. Pigula FA, Wald SL, Shackford SR, Vane DW. The effect of hypotension and hypoxia on children with severe head injuries. J Pediatr Surg. 1993;28 (3):310-314. doi:10.1016/0022-3468(93)90223-8

54. Manley G, Knudson MM, Morabito D, Damron S, Erickson V, Pitts L. Hypotension, hypoxia, and head injury: frequency, duration, and consequences. Arch Surg. 2001;136(10):1118-1123. doi:10.1001/archsurg.136.10.1118

55. Price DJ, Murray A. The influence of hypoxia and hypotension on recovery from head injury. Injury. 1972;3(4):218-224. doi:10.1016/0020-1383(72) 90104-0

56. Miller JD, Sweet RC, Narayan R, Becker DP. Early insults to the injured brain. JAMA. 1978;240 (5):439-442. doi:10.1001/jama.1978 03290050029011

57. McHugh GS, Engel DC, Butcher I, et al. Prognostic value of secondary insults in traumatic brain injury: results from the IMPACT study. J Neurotrauma. 2007;24(2):287-293. doi:10.1089/ neu.2006.0031

58. Davis DP, Dunford JV, Ochs M, Park K, Hoyt DB The use of quantitative end-tidal capnometry to avoid inadvertent severe hyperventilation in patients with head injury after paramedic rapid sequence intubation. J Trauma. 2004;56(4):808 814. doi:10.1097/01.TA.0000100217.05066.87

59. Davis DP. Early ventilation in traumatic brain injury. Resuscitation. 2008;76(3):333-340. doi:10. 1016/j.resuscitation.2007.08.004

60. Davis DP, Heister R, Poste JC, Hoyt DB, Ochs $M$, Dunford JV. Ventilation patterns in patients with severe traumatic brain injury following paramedic 
rapid sequence intubation. Neurocrit Care. 2005;2 (2):165-171. doi:10.1385/NCC:2:2:165

61. Manley GT, Hemphill JC, Morabito D, et al. Cerebral oxygenation during hemorrhagic shock: perils of hyperventilation and the therapeutic potential of hypoventilation. J Trauma. 2000;48 (6):1025-1032. doi:10.1097/00005373200006000-00005

62. Zornow MH, Prough DS. Does acute hyperventilation cause cerebral ischemia in severely head-injured patients? Crit Care Med. 2002;30(12):2774-2775. doi:10.1097/00003246 200212000-00026

63. Muizelaar JP, Marmarou A, Ward JD, et al. Adverse effects of prolonged hyperventilation in patients with severe head injury: a randomized clinical trial. J Neurosurg. 1991;75(5):731-739. doi:10. 3171/jns.1991.75.5.0731

64. Gaither JB, Spaite DW, Bobrow BJ, et al. Balancing the potential risks and benefits of out-of-hospital intubation in traumatic brain injury: the intubation/hyperventilation effect. Ann Emerg Med. 2012;60(6):732-736. doi:10.1016/j. annemergmed.2012.06.017

65. Denninghoff KR, Griffin MJ, Bartolucci AA, Lobello SG, Fine PR. Emergent endotracheal intubation and mortality in traumatic brain injury. West J Emerg Med. 2008;9(4):184-189.

66. Wang HE, Peitzman AB, Cassidy LD, Adelson $P D$, Yealy DM. Out-of-hospital endotracheal intubation and outcome after traumatic brain injury. Ann Emerg Med. 2004;44(5):439-450. doi:10. 1016/j.annemergmed.2004.04.008

67. Davis DP, Hoyt DB, Ochs M, et al. The effect of paramedic rapid sequence intubation on outcome in patients with severe traumatic brain injury. J Trauma. 2003;54(3):444-453. doi:10.1097/01.TA. $0000053396.02126 . C D$

68. Davis DP, Vadeboncoeur TF, Ochs M, Poste JC, Vilke GM, Hoyt DB. The association between field Glasgow Coma Scale score and outcome in patients undergoing paramedic rapid sequence intubation. J Emerg Med. 2005;29(4):391-397. doi:10.1016/j jemermed.2005.04.012

69. Feldman A, Hart KW, Lindsell CJ, McMullan JT. Randomized controlled trial of a scoring aid to improve Glasgow Coma Scale scoring by emergency medical services providers. Ann Emerg Med. 2015; 65(3):325-329.e2. doi:10.1016/j.annemergmed.2014 07.454

70. Bledsoe BE, Casey MJ, Feldman J, et al. Glasgow Coma Scale Scoring is often inaccurate. Prehosp Disaster Med. 2015;30(1):46-53. doi:10. 1017/S1049023X14001289

71. Maas Al, Stocchetti N, Bullock R. Moderate and severe traumatic brain injury in adults. Lancet Neurol. 2008;7(8):728-741. doi:10.1016/S1474-4422(08) 70164-9

72. Narayan RK, Michel ME, Ansell B, et al. Clinical trials in head injury. J Neurotrauma. 2002;19(5): 503-557. doi:10.1089/089771502753754037

73. Spaite DW, Hanlon T, Criss EA, Valenzuela TD, Meislin HW, Ross J. Prehospital data entry compliance by paramedics after institution of a comprehensive EMS data collection tool. Ann
Emerg Med. 1990;19(11):1270-1273. doi:10.1016/ S0196-0644(05)82286-3

74. Cummins RO, Chamberlain DA, Abramson NS, et al. Recommended guidelines for uniform reporting of data from out-of-hospital cardiac arrest: the Utstein Style: a statement for health professionals from a task force of the American Heart Association, the European Resuscitation Council, the Heart and Stroke Foundation of Canada, and the Australian Resuscitation Council. Circulation. 1991;84(2):960-975. doi:10.1161/01.CIR. 84.2 .960

75. Zaritsky A, Nadkarni V, Hazinski MF, et al. Recommended guidelines for uniform reporting of pediatric advanced life support: the Pediatric Utstein Style: a statement for healthcare professionals from a task force of the American Academy of Pediatrics, the American Heart Association, and the European Resuscitation Council. Resuscitation. 1995;30(2):95-115. doi:10. 1016/0300-9572(95)00884-V

76. Wang CH, Chou NK, Becker LB, et al. Improved outcome of extracorporeal cardiopulmonary resuscitation for out-of-hospital cardiac arrest: a comparison with that for extracorporeal rescue for in-hospital cardiac arrest. Resuscitation. 2014;85 (9):1219-1224. doi:10.1016/j.resuscitation.2014.06. 022

77. Callaway CW, Donnino MW, Fink EL, et al. Part 8: post-cardiac arrest care: 2015 american heart association guidelines update for cardiopulmonary resuscitation and emergency cardiovascular care. Circulation. 2015;132(18)(suppl 2):S465-S482. doi:10 1161/CIR.0000000000000262

78. Perkins GD, Jacobs IG, Nadkarni VM, et al; Utstein Collaborators. Cardiac arrest and cardiopulmonary resuscitation outcome reports: update of the Utstein Resuscitation Registry Templates for Out-of-Hospital Cardiac Arrest: a statement for healthcare professionals from a task force of the International Liaison Committee on Resuscitation (American Heart Association, European Resuscitation Council, Australian and New Zealand Council on Resuscitation, Heart and Stroke Foundation of Canada, InterAmerican Heart Foundation, Resuscitation Council of Southern Africa, Resuscitation Council of Asia); and the American Heart Association Emergency Cardiovascular Care Committee and the Council on Cardiopulmonary, Critical Care, Perioperative and Resuscitation. Circulation. 2015;132(13):1286-1300 doi:10.1161/CIR.0000000000000144

79. MacKenzie EJ, Rivara FP, Jurkovich GJ, et al. A national evaluation of the effect of trauma-center care on mortality. NEngl J Med. 2006;354(4):366378. doi:10.1056/NEJMsa052049

80. MacKenzie EJ, Weir S, Rivara FP, et al. The value of trauma center care. J Trauma. 2010;69(1): 1-10. doi:10.1097/TA.0b013e3181e03a2

81. Spaite DW, Bobrow BJ, Stolz U, et al; Arizona Cardiac Receiving Center Consortium. Statewide regionalization of postarrest care for out-of-hospital cardiac arrest: association with survival and neurologic outcome. Ann Emerg Med. 2014;64(5): 496-506.e1. doi:10.1016/j.annemergmed.2014.05 028
82. Maas Al, Hukkelhoven CW, Marshall LF, Steyerberg EW. Prediction of outcome in traumatic brain injury with computed tomographic characteristics: a comparison between the computed tomographic classification and combinations of computed tomographic predictors. Neurosurgery. 2005;57(6):1173-1182. doi:10.1227/01.NEU.0000186013.63046.6B

83. Klemen P, Grmec S. Effect of pre-hospital advanced life support with rapid sequence intubation on outcome of severe traumatic brain injury. Acta Anaesthesiol Scand. 2006;50(10):12501254. doi:10.1111/j.1399-6576.2006.01039.x

84. Schüttler J, Schmitz B, Bartsch AC, Fischer M. The efficiency of emergency therapy in patients with head-brain, multiple injury. Quality assurance in emergency medicine. Anaesthesist. 1995;44(12): 850-858.

85. Denninghoff KR, Nuño T, Pauls $Q$, et al. Prehospital intubation is associated with favorable outcomes and lower mortality in ProTECT III. Prehosp Emerg Care. 2017;21(5):539-544. doi:10. 1080/10903127.2017.1315201

86. Stocchetti N. Risk prevention, avoidable deaths and mortality-morbidity reduction in head injury. Eur J Emerg Med. 2001;8(3):215-219. doi:10. 1097/00063110-200109000-00009

87. Bernard SA, Nguyen V, Cameron P, et al. Prehospital rapid sequence intubation improves functional outcome for patients with severe traumatic brain injury: a randomized controlled trial. Ann Surg. 2010;252(6):959-965. doi:10.1097/ SLA.0b013e3181efc15f

88. Davis DP, Peay J, Sise MJ, et al. The impact of prehospital endotracheal intubation on outcome in moderate to severe traumatic brain injury. J Trauma. 2005;58(5):933-939. doi:10.1097/01.TA 0000162731.53812 .58

89. Winchell RJ, Hoyt DB; Trauma Research and Education Foundation of San Diego. Endotracheal intubation in the field improves survival in patients with severe head injury. Arch Surg. 1997;132(6):592 597. doi:10.1001/archsurg.1997.01430300034007

90. Bulger EM, Copass MK, Sabath DR, Maier RV, Jurkovich GJ. The use of neuromuscular blocking agents to facilitate prehospital intubation does not impair outcome after traumatic brain injury. J Trauma 2005;58(4):718-723. doi:10.1097/01.TA. 0000159239.14181.BC

91. Stockinger ZT, McSwain NE Jr. Prehospital endotracheal intubation for trauma does not improve survival over bag-valve-mask ventilation. J Trauma. 2004;56(3):531-536. doi:10.1097/01.TA. 0000111755.94642 .29

92. Davis DP, Stern J, Sise MJ, Hoyt DB. A follow-up analysis of factors associated with head-injury mortality after paramedic rapid sequence intubation. J Trauma. 2005;59(2):486-490. doi:10. 1097/00005373-200508000-00037

93. Ford I, Norrie J. Pragmatic trials. NEngl J Med. 2016;375(5):454-463. doi:10.1056/NEJMra1510059 